\title{
Minería y territorio en México: \\ tres modelos históricos de implantación socioespacial
}

\section{Juan Luis Sariego Rodríguez}

La historia de México revela tres modelos de organización territorial de la minería. Los reales de minas fueron los núcleos urbanos coloniales de la integración económica y política así como del mestizaje cultural. En el siglo xix, las empresas extranjeras utilizaron un modelo de implantación basado en la gestión urbana de los enclaves mineros, y en su relativa autonomía, del entorno económico y social. La pequeña minería ha logrado sobrevivir en comunidades aisladas, gracias a su simbiosis con la agricultura campesina, sin llegar a producir asentamientos estables.

\section{La huella de la minería en el territorio}

Los mineros mexicanos se precian orgullosamente de haber sido históricamente la vanguardia colonizadora de muchas regiones del territorio nacional. Y no les falta razón: las rutas de la plata desde el altiplano central hasta los desiertos de Nuevo México (en el suroeste de Estados Unidos), y desde la capital del virreinato hasta los puertos de embarque de Veracruz y Acapulco han sido durante siglos los ejes vertebrales de las comunicaciones del país. A una escala microrregional, muchos de los viejos senderos frecuentados por arrieros mineros, los "caminos reales", siguen siendo hoy la única vía de acceso a muchos pueblos perdidos en las vertientes de la Sierra Madre.

La red urbana del país revela también y hasta el presente, el peso de la historia minera: muchas de las ciudades y actuales capitales de estados de la República como Guanajuato, San Luis Potosí, Pachuca, Taxco, Zacatecas, Chihuahua, Saltillo y Durango, entre otras, tienen su origen en el afán de los españoles por colonizar territorios con enormes yacimientos de oro y plata. Otras, en cambio, testimonian la impronta de los capitalistas mineros de origen europeo y norteamericano.

En medio de una gran pluralidad y diversidad de asentamientos ligados a la minería, tres modelos de comunidad parecen destacar. Cada uno de ellos revela una forma particular de relación entre la actividad económica, la estructura social y el territorio. Se trata de modelos que tienen una raíz y una evolución histórica diferentes, que responden a una lógica productiva también distinta y que expresan en el espacio esquemas de microsociedades con características peculiares. 


\section{Los reales de minas. El modelo de la sociedad colonial minera}

La preocupación de la Corona española por controlar la extracción y el comercio de la plata en las colonias americanas dio lugar a la aparición de un tipo particular de comunidades: los reales de minas. En ellas, como en ningún otro espacio de la sociedad colonial, se hizo presente el aparato de Estado español a través de una serie de instituciones orientadas a fiscalizar los impuestos mineros, monopolizar la venta del azogue en las cajas reales, controlar la operación de las casas de moneda, asegurar la donación de los propietarios de minas del "quinto real" destinado a las obras de la Iglesia, organizar un dinámico mercado de mano de obra indígena a través de la encomienda, el repartimiento y el comercio de esclavos negros; asegurar la producción de alimentos, animales de carga, forrajes, cueros y otros materiales para las minas, y en general, fomentar todas las actividades ligadas al ramo minero.

Alrededor de los reales de minas fue creándose un hinterland de economías satélites estrechamente vinculadas con los centros mineros, y en muchos casos, integradas, en términos de su propiedad y su mercado, a la lógica de funcionamiento de los complejos mineros. En muchas zonas de México este esquema de articulación entre centros urbanos mineros, haciendas agroganaderas y comunidades indígenas fue el origen de la conformación de regiones. ${ }^{1}$

En todos estos reales de minas se observa un modelo urbano similar. El centro urbano preside y articula funcionalmente las actividades mineras a través de las cajas reales, donde el gobierno monopolizaba la venta del mercurio fiscalizando así la producción de oro y plata, las "casas de ensaye", donde se acuñaba la moneda, los mercados, etcétera. Pero sobre todo, los espacios monumentales en el núcleo urbano (catedrales, palacios virreinales, iglesias, conventos, hospitales, tribunales, colegios, casas de beneficencia, etc.), rememoran la centralidad del poder político y religioso en la más pura tradición española. En el entorno más cercano a esta área, se sitúan las calles y barrios ligados al comercio y a los gremios que vivían a expensas de la riqueza minera (plateros, talabarteros, sastres, etcétera).

Sin negar la centralidad de los espacios monumentales, la estructura espacial de estos "reales" trasluce las verdaderas raíces

1 En particular, éste es el caso de varias de las regiones más importantes de México como el Bajío (Guanajuato, San Luis Potosí), la Sierra Gorda de Querétaro, Zacatecas-Fresnillo y su entorno agroganadero, Pachuca-Real del Monte y las comunidades indígenas de la Huasteca y valle del Mezquital, el área de Hidalgo del Parral, etcétera (Brading, 1975; Bakewell, 1976; West, 1949). 
de su fundación y esplendor: bocaminas, "haciendas de beneficio" y "talleres de maestranza" circundan la ciudad, sobre cerros o pendientes laderas. Vetas, minas y plantas metalúrgicas llevan el nombre de un santo patrón o de algún rico conde, marqués o comerciante español propietario del fundo.

Junto a ellas, segregados del centro y de forma por demás anárquica, se apiñan los barrios mineros, también bajo la advocación de un santo o, más comúnmente, con el nombre del lugar de origen desde donde han migrado los obreros de oficio y trabajadores indios, negros y mestizos de esas minas. En contraste con el centro de la ciudad, éste es el espacio del mestizaje cultural en el que florecen las tradiciones de los oficios mineros y en el que la vecindad revela el predominio de la familia extensa indígena, a través de la cual se perpetuan los lazos de continuidad con la comunidad de origen. La durabilidad de estos asentamientos es tan incierta como lo son los ciclos de bonanzas y borrascas que presiden la economía minera.

Los reales de minas son también los espacios del consumo suntuario donde van a parar las fortunas que salen del subsuelo: la arquitectura monumental combina versiones locales de estilos renacentista, barroco, neoclásico y rococó, y en los espacios interiores de esta arquitectura, los grabados, objetos ornamentales, cofres, rejas, esculturas, armas, arneses, herramientas, utensilios de cocina, así como la imaginería religiosa, permiten descubrir el grado de penetración de los parámetros de la cultura española en la vida cotidiana colonial.

Tras la independencia, casi todos los reales de minas se vieron afectados por la crisis gradual de la minería de los metales preciosos, máxime en los casos donde la obsolescencia tecnológica y el agotamiento de los yacimientos hizo inviable cualquier intento de restauración minera. Aunque algunos de estos centros se han ruralizado, la mayoría en cambio, vivieron a principios de este siglo un cierto periodo de auge, derivado de la inversión extranjera, y hoy se han convertido en importantes capitales regionales con una estructura económica y ocupacional más dependiente del comercio y de los servicios pero sin que la minería haya dejado de ser una de sus fuentes de riqueza. En cualquier caso, el legado de infraestructuras útiles que el pasado minero dejó en estos territorios, ha sido reutilizado para dinamizar la economía de estos centros urbanos convertidos hoy en capitales de estados y regiones. 


\section{Los minerales. La impronta del capital extranjero}

Entre 1880 y 1910, la minería mexicana vivió un periodo de auténtica restructuración y modernización productivas que siguió a varias décadas de inestabilidad y franco estancamiento y que fue en gran medida una empresa concebida, dirigida y orientada por los intereses imperialistas de consorcios extranjeros, particularmente norteamericanos.

Esta nueva minería de enclave que trajo el siglo tuvo además un claro signo colonizador. La frontera del territorio minero, hasta entonces circunscrita a los límites del área mesoamericana, comenzó a expandirse hacia los estados del norte fronterizo en los que, una vez controlado el peligro apache y consumado un proceso de expropiación de bosques y tierras comunales, las grandes empresas extranjeras denunciaron y se apropiaron de enormes yacimientos de minerales. ${ }^{2}$

Para hacer posible la operación de muchos de estos complejos, los empresarios no sólo tuvieron que reunir cuantiosas inversiones, sino que además tuvieron que crear vías de comunicacion y construir pueblos mineros en zonas deshabitadas, aisladas, desérticas o serranas. Sólo así fue posible atraer a las minas una mano de obra siempre escasa y reacia a proletarizarse, más aún teniendo en cuenta la abierta competencia con las haciendas agrícolas, las plantaciones del sur de Estados Unidos y las empresas constructoras del ferrocarril.

Los pueblos mineros que surgieron de este impulso colonizador derivaron de una concepción empresarial y adquirieron una fisonomía urbana muy distinta de aquellas que habían predominado en los reales de minas. Quizás por eso, estas comunidades fueron denominadas desde entonces, tanto en el lenguaje técnico como en el habla común y aun en el vocabulario de los corridos de la época, con un término distintivo: "los minerales". Al referirse a ellos, dos factores llaman particularmente la atención: su aislamiento y su estrecha dependencia del poder empresarial.

El aislamiento en sentido geográfico y espacial es explicable si se tiene en cuenta el proceso de colonización que ya antes hemos señalado: lejanos de los centros urbanos y enclavados en áreas de difícil acceso, los minerales representaron una especie de rup-

2 El norte de México, considerado entonces la tierra promisoria de los mineros, atraía en $1900,75 \%$ de las inversiones mineras norteamericanas, aportaba más de $70 \%$ del valor de la producción minera nacional y ocupaba cerca de $60 \%$ de los mineros, a los que ofrecía salarios casi dos veces superiores a los de las regiones mineras del centro del país. 
tura radical y modernizante con un paisaje despoblado, o en el mejor de los casos, con escasos signos de agricultura a pequeña escala, explotación comunal de bosques, o enormes latifundios de ganadería menor con una bajo índice de ocupación real de la tierra.

Los minerales constituyeron un tipo muy particular de comunidad caracterizado por la monoocupación y la continuidad entre el ámbito fabril de la producción y el espacio urbano de la reproducción, permeados ambos por el poder empresarial. Para fijar al trabajo a una mano de obra del más variado origen étnico y social y para asegurar su reproducción, el estado delegó en los empresarios extranjeros todo tipo de concesiones y atribuciones en materia de urbanización e implantación de equipamientos colectivos.

El diseño urbano resultante de la iniciativa patronal respondió casi siempre a una clara filosofía del espacio: la de concebir las ciudades mineras como una prolongación de la vida laboral, un factor más en la operación productiva de los complejos minero-metalúrgicos y una reserva segura de trabajo capaz de compensar el desgaste, la rotación y la inestabilidad de la mano de obra, derivados de las condiciones del mercado de trabajo minero.

La continuidad entre el ámbito laboral y el espacio urbano fue garantizada a través de un férreo control empresarial en estos dos órdenes. Tras monopolizar la propiedad del suelo y de los recursos urbanos, las compañías extranjeras diseccionaron el espacio de los minerales con una clara lógica segregacionista, separando los barrios y el acceso a los servicios de acuerdo con el origen étnico de sus pobladores y su ubicación dentro del esquema de la división del trabajo. Calles, plazas, mercados, templos, colonias, viviendas, escuelas, comercios, tiendas de raya, hospitales, clínicas, cines, teatros, clubes, campos deportivos y centros de ocio, todos ellos erigidos por iniciativa patronal, sirvieron para separar a los directivos y mandos superiores extranjeros de los trabajadores, e incluso a éstos entre sí, de acuerdo con su nacionalidad, condición étnica o categoría laboral. Pero sobre todo, este modelo de implantación espacial expresó el carácter de una microsociedad cerrada hacia sí misma y en todo dependiente del paternalismo empresarial. Todo ello contribuyó significativamente a diferenciar estos núcleos de población del resto de la sociedad nacional circundante.

En abierto contraste con el sistema de integración territorial que propiciaron los reales de minas del periodo colonial, el crecimiento urbano y el dinamismo industrial de los minerales no logró crear economías satélites en el hinterland circundante, y ni siquiera dinamizarlas en aquellos casos donde existían pequeños núcleos de actividades agrícolas, ganaderas, artesanales o comerciales. 
Desde la década de los cuarenta, los minerales han ido perdiendo por varias razones su carácter de enclave. En primer lugar, la minería se ha ido integrando al conjunto de la industria del país y tanto el gobierno como los inversores nacionales han asumido un mayor control de las empresas. En segundo lugar, la consolidación del sindicalismo trajo a la arena social de los minerales un nuevo sujeto político capaz de cuestionar las prerrogativas que el capital extranjero detentaba. Este protagonismo obrero, consentido y fomentado por los gobiernos posrevolucionarios, mermó sustancialmente y reguló el monopolio de las empresas en la gestión urbana de los minerales.

La contracción del mercado laboral minero y la ampliación de un sector terciario independiente de las empresas han contribuido también a diversificar las oportunidades y los grupos ocupacionales. Los minerales, en fin, se emancipan cada vez más de las empresas, dejan de ser exclusivamente una comunidad laboral y se convierten en un segmento más de la sociedad civil; pierden su aislamiento y se integran gradualmente a la economía, a la sociedad y a la cultura nacionales. Como ejemplos de este tipo de comunidades mineras pueden citarse Cananea (Sonora), Nueva Rosita (Coahuila) y Santa Rosalía (Baja California), entre otros.

\section{Inestabilidad y simbiosis con la agricultura: la persistencia de las pequeñas comunidades mineras}

Cualquiera que revise un mapa minero actual de México se sorprenderá al encontrar una gran cantidad de comunidades que fueron, en sus orígenes o en algún momento de su historia, pujantes centros mineros y que hoy, o han quedado reducidos a la condición de pueblos fantasmas deshabitados, o son localidades donde las actividades extractivas resurgen y decaen con una frecuencia inusitada. Muchas de estas comunidades revelan una larga tradición de simbiosis, siempre inestable y precaria, entre la agricultura campesina y la minería a pequeña escala.

Dos factores parecen ser la causa principal que explica esta incapacidad de la minería para convertirse en el eje dinamizador de la demografía y de la economía de estas comunidades: la dispersión de los yacimientos en un territorio de difícil acceso, y por ende, la notoria desconexión de estos pueblos respecto a las redes de comunicaciones, a las fuentes de energía eléctrica y a las plantas metalúrgicas donde se benefician, funden y refinan los minerales.

Esta pequeña y mediana minería tiene en efecto un territorio muy preciso, el de la Sierra Madre, principalmente en su vertiente 
occidental, zona conformada por rocas de origen ígneo y bosques. Geográficamente, se trata de una región con una gran elevación sobre el nivel del mar (más de $3000 \mathrm{~m}$ en algunos puntos) y con desniveles promedio sobre la planicie costera de 1500 a $2500 \mathrm{~m}$, barrancas en las que se localizan varias cuencas fluviales orientadas al Pacífico. Comprende la porción serrana de los estados de Sonora, Sinaloa, Durango, Zacatecas, Aguascalientes, Jalisco y Nayarit (véase mapa 1). Desde el punto de vista minero, la Sierra Madre occidental es particularmente rica en yacimientos de oro y plata, minerales que se presentan en forma de vetas y con leyes notoriamente más altas que en otras regiones mineras del país.

Por su carácter inaccesible, este territorio se ha convertido históricamente en una zona de refugio para muchos grupos indígenas (tarahumaras, guarojíos, pimas, ópatas, tepehuanes, huicholes, etc.). La mayoría de ellos se instalaron en estas tierras, en sucesivas oleadas, a raíz de la presión que ejercieron desde la época colonial diferentes grupos colonizadores. Con ellos convive hoy una población mestiza cuyo asentamiento en la zona derivó fundamentalmente de la colonización minera. Igual que las sociedades indias, también otros grupos han encontrado en la sierra una zona de refugio y resistencia: en el siglo pasado fue éste el territorio del bandolerismo y hoy constituye una de las regiones predilectas del narcotráfico.

Las características geográficas y sociales del territorio donde se ubican estos ricos yacimientos han constituido desde siempre una seria barrera para su aprovechamiento y explotación a gran escala. Esta desventaja, que no era tan marcada hasta el siglo XIX (cuando el acarreo de los minerales se realizaba en todas partes con bestias y las técnicas minerometalúrgicas eran homogéneas en todo el país), se acrecentó notoriamente a finales del siglo ya que otras regiones mineras pudieron acceder a una significativa reducción de los costos de producción derivada de la llegada del ferrocarril, el uso de la electricidad, la mecanización de las labores de extracción y la instalación de fundiciones.

Dos coyunturas vinieron a agravar más esta situación: los levantamientos armados de los años de la Revolución mexicana (1910-1920) y la drástica caída de los precios de los metales durante la gran depresión de 1929-1932. Como ha tratado de mostrar un historiador francés (Guerra, 1983) en un sugerente artículo, los primeros triunfos armados de la Revolución tuvieron como escenario este territorio de pequeña minería serrana, particularmente sensible a todo tipo de crisis agrícolas o mineras, y sus protagonistas fueron en muchos casos trabajadores despedidos entre 


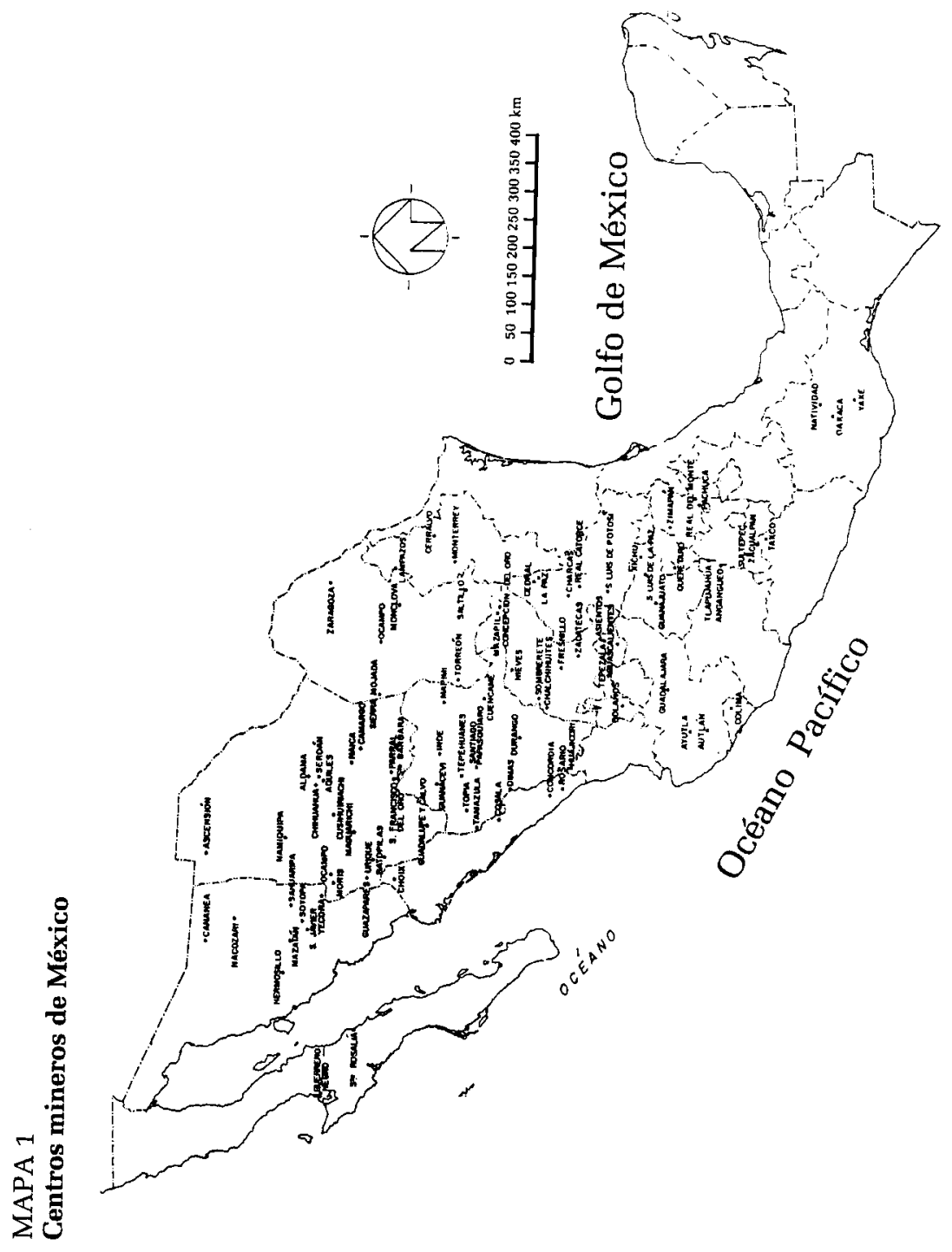


1906 y 1910 a raíz de una de esas crisis. En los años siguientes, el control que los orozquistas y villistas ejercieron sobre las caravanas de arrieros en territorio serrano acabó por propiciar un cierre masivo de minas y una repatriación generalizada de capitales. Durante los años veinte, cuando esta minería serrana comenzaba a recuperarse de los estragos de la Revolución, acabó por sucumbir ante los primeros síntomas de la crisis mundial de 1929.

Desde entonces, las grandes compañías, desanimadas por los enormes costos que implicaba el trazado de vías férreas, la introducción de la electricidad, el acceso a los mercados y la construcción de pueblos mineros, relegaron esta zona serrana a una condición marginal dentro de la geografía minera.

Esta condición marginal poco ha cambiado desde entonces hasta hoy. Las empresas mineras no han modificado en esencia su estrategia: sólo algunas de mediana capacidad han instalado complejos para explotar, en un tiempo relativamente corto, yacimientos previamente detectados y particularmente ricos; después de eso han preferido abandonar la sierra. Los gobiernos federal y estatales, por su parte, han optado por concentrar sus inversiones en la creación de infraestructuras para la explotación, no pocas veces irracional, del otro recurso estratégico de este territorio, la riqueza de sus bosques, de la que dependen, en buena medida, la industria y la exportación de maderas y celulosa del país.

$\mathrm{El}$ abandono de la infraestructura de comunicaciones de estas poblaciones serranas, la carencia de combustibles, maquinaria y energía eléctrica, unidos a su enorme lejanía de las plantas de beneficio y fundición (en ocasiones de más de $2000 \mathrm{~km}$ ), han sumido a estas comunidades en una condición de atraso crónico. La crisis de esta minería ha significado también una notoria disminución del intercambio comercial y de la integración económica entre los núcleos serranos y las poblaciones costeras del Pacífico, territorios ambos estrechamente articulados durante todo el periodo colonial y aun hasta hace setenta años.

A pesar de todo ello, no puede decirse que la vocación minera de estas comunidades, muchas de las cuales se resisten a convertirse en pueblos fantasmas, haya desaparecido por completo; y aún parece que tiene su propia racionalidad económica. El pequeño minero serrano logra sobrevivir explotando a muy baja escala minerales con un muy alto contenido de oro y plata, utilizando para ello arcaicos métodos metalúrgicos, basados en el principio de la amalgamación, que no requieren más energía que la de un arroyo caudaloso ni más materias primas que unos gramos de mercurio. Son los "gambusinos", "chiveadores", "tahoneros", "puntistas" o "lavadores" de las profundas barrancas de la Sierra 
Madre, quienes combinan en muchos casos su vieja tradición de oficio con la siembra del maíz y del frijol.

Por cuanto hemos dicho hasta aquí, podrá entenderse que el perfil social de este tipo de comunidades difiere notoriamente del de los minerales y los reales de minas. $\mathrm{Ni}$ empresas ni sindicatos tienen aquí cabida, unas por el riesgo de la inversión y la inseguridad de las ganancias, otros por la incertidumbre del trabajo y la precariedad del empleo. Las relaciones de trabajo entre propietarios y explotadores de las minas tampoco están mediadas por el salario, sino casi siempre, por el trabajo "al partido": los concesionarios de la mina adelantan al pequeño minero materiales explosivos y algunas herramientas y adquieren de éste una parte del mineral extraído. En esta operación pueden incluso mediar los comerciantes locales, financiando los costos o rescatando la producción final para después comercializarla en las plantas metalúrgicas.

Desde varias perspectivas puede decirse que estas pequeñas comunidades constituyen una frontera minera. Su inaccesibilidad espacial las ha colocado fuera de las innovaciones tecnológicas y de la voracidad de las grandes empresas mineras. Desde el punto de vista laboral, estos núcleos conservan aún muchos rasgos de autonomía productiva propios de etapas anteriores a la división capitalista del trabajo y a la especialización de los oficios mineros. Desde el punto de vista étnico la sierra sigue siendo todavía hoy una frontera que separa dos culturas. Dos formas también de entender la relación del hombre con las riquezas del subsuelo.

\section{Bibliografía}

Bakewell, P.J. (1976), Minería y sociedad en el México colonial. Zacatecas (1546-1700), México, Fondo de Cultura Económica.

Bambirra, V. (1974), El capitalismo dependiente latinoamericano, México, Siglo XXI Editores.

Bernstein, M.D. (1964), The Mexican Mining Industry. 1890-1950. A Study of the Interaction of Politics, Economics and Technology, Nueva York, State University of New York.

Brading, D.A. (1975), Mineros y comerciantes en el México borbónico, 1763-1810, México, Fondo de Cultura Económica.

Bulmer, W.I. (1975), "Sociological models of the mining community", en The Sociological Review, XXXII.

Cardoso, F.H. y E. Faletto (1979), Dependencia y desarrollo en América Latina, México, Siglo XXI Editores.

Davis, H. (s.f.), "Company-Towns", en Encyclopedia of the Social Sciences, vol. IV, pp. 119-123. 
González Reyna, J. (1956), Geología del estado de Chihuahua, Chihuahua. Guerra, F.X. (1983), “Territorio minado. Más allá de Zapata en la Revolución Mexicana”, en Nexos, núm. 65, mayo.

Katz, F. (1976), La servidumbre agraria en México en la época porfiriana, México, Secretaría de Educación Pública (Colecc. SepSetentas).

Kerr, C. y A. Siegel (1954), "Inter-industry propensity to strike", en A. Flandres, en Collective Bargaining, Penguin Books.

Marcosson, I. (1949), Metal Magic. The Story of the American Smelting and Refining Company, Nueva York, Farrar, Strauss and Company.

Marques de la Croix (1771), Instrucción que deja a su sucesor Antonio María Bucarelli, México.

Mendizábal, M.O. (1980), La minería y la metalurgia mexicanas (15201943), México, Centro de Estudios Históricos del Movimiento Obrero.

Palerm, A. (1979), "Sobre la formación del sistema colonial: apuntes para una discusión", en Enrique Florescano, Ensayos sobre el desarrollo económico de México y América Latina (1500-1975), México, Fondo de Cultura Económica.

Powell, P.H. (1952), Soldiers, Indians and Silver. The Northward Advance of New Spain, 1550-1600, Berkeley and Los Angeles, University of California Press.

Sariego, J.L (1988), Enclaves y minerales en el norte de México. Historia social de los mineros de Cananea y Nueva Rosita. 1900-1970, México, Ediciones de la Casa Chata-CIESAS.

— L. Reygadas, M.A. Gómez y J. Farrera (1988), El Estado y la minería mexicana. Política, trabajo y sociedad durante el siglo XX, México, Fondo de Cultura Económica.

Skougor, H.E. (1921), "Rosita, a carefully planed City; pleasing, comfortable and hygienic", en Coal Age, vol. 19 (22 y 23), junio.

West, R. (1949), "The Mining Community of Northern New Spain: The Parral Mining District", en Iberoamericana (30), Berkeley and Los Angeles, University of California Press.

Zapata, F. (1977), "Enclaves y sistemas de relaciones industriales en América Latina", en Revista Mexicana de Sociología, abril-junio. 
- $\ldots$. 